\section{The use of olfactory cues in solving a visual discrimination task}

\author{
B. MICHAEL THORNE and A. LAMAR O'BRIEN \\ Mississippi State University, State College, Mississippi 39762
}

Albino rats, trained in a miniaturized WGTA, were found to learn an olfactory discrimination despite the fact that visual cues were relevant and obvious. The results provide a further warning against the use of macrosmatic animals in visual discrimination tasks in which olfactory cues may be relevant.

Because of the continued use of macrosmatic animals in learning experiments, the possibility exists that the current literature is contaminated with studies in which the Ss utilized olfactory cues rather than the cues intended by the $E$. The number of recent studies dealing with the "odor hypothesis" and with olfactory cues in visual discrimination problems indicates that some awareness of the problem exists (Phillips, 1968, 1970; Seago, Ludvigson, \& Remly, 1970; Topping \& Cole, 1969; Wasserman \& Jensen, 1969). The present study details an example of olfactory learning in a situation in which visual cues were both relevant and obvious.

\section{METHOD}

The Ss were 22 adult male albino rats. Following discrimination training, 10 animals were enucleated, 5 were bulbectomized, and 7 served as unoperated controls. In addition, 6 of the enucleated animals were bulbectomized after retention testing. Both enucleations and bulbectomies were performed under Nembutal anesthesia. In bulbectomizing the animals, an attempt was made to remove all of the olfactory bulbs anterior to the frontal poles.

The training apparatus consisted of a miniaturized WGTA described fully by Rollin, Shepp, and Thaller (1963). Stimulus cards were made from $2 \times 2$ in. pieces of posterboard pasted on $2 \times 2$ in. bases of $1 / 4$-in. plywood. A pair of gray cards was used to train the animals to expose the reward, while a white-black (W-B) pair was used for discrimination training. The white card was painted with Alkyd Sani-flat white paint manufactured by Benjamin Moore \& Co., and the black card was painted with Jones-Blair No. 934 black (Chalkboard slating). Throughout discrimination training and retention testing, the W-B cards were repainted approximately once weekly and were cleaned with water between Ss.

From 3-5 days prior to training, all animals were placed on a $23-\mathrm{h} 50-\mathrm{min}$ water-deprivation schedule. After the animals had been trained to push a gray card to expose the reward wells within a 2 -min time period, discrimination training was initiated. Animals were trained to push the white card and to avoid the black stimulus. Both wells were baited with one drop of tap water on each trial, and a small block was placed behind the black card to prevent uncovering of the well. The noncorrection method was used primarily with occasional correction trials given to maintain responding. Discrimination training consisted of 20 trials per day with a 15-sec ITI. Animals were trained to a criterion of 18 correct responses in 1 day, a response being defined as any detectable deflection of a stimulus card. The position of the positive and negative cards was varied according to a modified Gellerman sequence. Following a 3- to 14-day recovery period, retention testing began and consisted of relearning the original problem. Abbreviated preliminary training was given if the animal was reluctant to respond after the recovery period. Savings scores based upon the number of errors made prior to a criterion run were calculated for each animal.

\section{RESULTS}

A comparison of savings scores between the enucleation group and the control group revealed that enucleation had little effect upon retention $(\mathrm{U}=33.5)$.

Although all enucleated animals were able to relearn the discrimination, the additional removal of the olfactory bulbs in six animals rendered them incapable of relearning within the time limit imposed. Specifically, three enucleated and bulbectomized animals were terminated after having made twice as many errors as in original learning, while the remaining three were sacrificed after making the same number of errors made originally.

To test the possibility that the inability to relearn after enucleation and bulbectomy might be a function of the combination of the two operations, five Ss were bulbectomized after discrimination training. Retention following bulbectomy was significantly poorer than control retention $(U=5, p=.024)$ and significantly worse than retention after enucleation $(U=7, p<.025)$. The animals were, however, able to relearn the task.

\section{DISCUSSION}

The results of the present study suggest that in a small-animal WGTA most rats will use an olfactory cue in preference to a visual one when both are relevant to the discrimination.

Phillips (1968), in a study designed to examine the use of olfactory cues in a visual discrimination task, hypothesized that the olfactory cue employed was an odor left by the animal on either the positive or the negative door. A more likely possibility in the present experiment is that the olfactory cues utilized came from the different odors of the white and black paint. Odors left by the animals on the cards would seem to be ruled out by the frequent paintings given to the discriminanda. In addition, the cards were always repainted before retention testing.

A pilot study indicated that the phenomenon detailed by the present study may not be restricted to the specific brands of paint described. When trained with cards sprayed with flat black and flat white paint of the same brand (Gibson), five of seven rats had better than $50 \%$ retention following enucleation. Thus, in a discrimination task requiring macrosmatic animals to push discriminanda with their nostrils, adequate controls must be used to prevent the animals from employing olfactory cues to make the discrimination.

\section{REFERENCES}

PHILLIPS, D. S. Olfactory cues in visual discrimination problems. Physiology \& Behavior, 1968, 3, 683-685.

PHILLIPS, D. S. Effects of olfactory bulb ablation on visual discrimination. Physiology \& Behavior, 1970, 5, 13-15. ROLLIN, A R SHEPP B. E. \& THALLER, K. E. A modified Wisconsin General Test Apparatus for the rat. American Journal of Psychology, 1963, 76, 500-502.

SEAGO, J. D., LUDVIGSON, H. W. \& REMLEY, N. R. Effects of anosmia on apparent double alternation in the rat. Journal of Comparative \& Physiological Psychology, 1970, 71, 435-442.

TOPPING, J. S., \& COLE, J. M. A test of the odor hypothesis using Mongolian gerbils and a random trials procedure. Psychonomic Science, 1969, 17, 183-184.

WASSERMAN, E. A., \& JENSEN, D. A. Olfactory stimuli and the "pseudo-extinction" effect. Science. $1969,166,1307-1309$. 